\title{
Growth of Aligned Carbon Nanotubes on Different Metal Substrates
}

\author{
Le-Hao $\mathrm{CHAI}^{1, \mathrm{a}}$,Xin-Hua $\mathrm{LI}^{1, \mathrm{~b}}$,Sen $\mathrm{ZHANG}^{1, \mathrm{c}}$,Fei WANG ${ }^{1, \mathrm{~d}}$, Hang \\ YANG $^{1, e}$, Shuai QIAO ${ }^{1, f}$ and Xue-Ao ZHANG ${ }^{1, g^{*}}$ \\ College of Science, National University of Defense Technology, Changsha 410073, China \\ achailh@foxmail.com, ${ }^{9}$ xazhang@nudt.edu.cn \\ ${ }^{*}$ Corresponding author
}

Keywords: Chemical Vapor Deposition, Metal Substrate, Carbon Nanotubes

\begin{abstract}
Vertically aligned carbon nanotubes (VACNTs) grown on metal substrates are of great importance for their applications in thermal and electrical devices. However, synthesizing better quality and long CNTs on metal substrates is still a big challenge. We have synthesized vertically aligned multiwalled carbon nanotubes (MWCNTs) on different metal substrates (i.e. copper and iron)by chemical vapor deposition and vertically aligned CNTs with lengths ranging from 2 to 400 $\mu$ mwere obtained. Moreover, the length of CNT on iron substrate has reached over $1 \mathrm{~mm}$, whichis relatively high CNT arrays using CVD on metal substrate to date.
\end{abstract}

\section{Introduction}

Since the discovery of Iijima in 1991[1], carbon nanotubes (CNTs) have attracted much attention due to the good chemical stability, a high aspect ratio geometry, low coefficient of thermal expansion, high thermal[2]as well as electrical conductivity[3] and mechanical strength[4]. CNTs can be employed as thermal interface materials (TIMs)in microelectronic packaging, electrode materials in energy storage cells[11] and super capacitors, field emission electron sources in flat panel displays[12,13]as well ase-beam lithography equipment and so on[5-10]. As discussed above, high electrical and thermal conductivity at room temperature [14]) are required for these applications, which usually need metal substrates(e.g. copper or iron) to connect with CNTs. However, the majority substrates for CNT growth are still the silicon [23-25], because better quality and high array can be easily got on silicon substrate by water-vapor-assisted CVD. Afterwards, CNT has to be transferred to the metal substrate for any applications requirements. As for the metal substrate, because of a high surface energy, catalyst will easily diffuse into the metal substrate and do not form nanoparticles, which has already been observed on Feand $\mathrm{Cu}$ substrate [15].Although a few papers have reported syntheses of CNT on various metal substrates, there are still big challenges [16-21]in this issue, such as poor alignment and more defects in the synthetized CNTs[22].Thus, synthesizing high-quality VACNTs on different metal substrates is urgently needed. In this paper, we report an easy progress on fast synthesis of high-quality VACNTs on different metal substrates through acommon thermal CVD process without water-vapor-assisted.

\section{Experimental Section}

Materials. Industrial-gradeacetylene, industrial-grade argon and hydrogen for the synthesis of our CNTs in which industrial-grade acetylene was carbon source. A thin layer of $2 \mathrm{~nm}$ Fe was used as catalyst and 30nm $\mathrm{Al}_{2} \mathrm{O}_{3}$ was usedas buffer layer on the metal substrate. Copper foil with thicknesses of $132 \mu \mathrm{m}$, iron foil with thicknesses of $380 \mu \mathrm{m}$, copper column with thicknesses of $1.2 \mathrm{~cm}$ and iron column with thicknesses of $0.9 \mathrm{~cm}$ were used as metal substrates for aligned CNT growth.

CVD Reactor Operations. We used CVDto synthesis of aligned CNTs, which was performed in a horizontal quartz tube (5 cm in diameter and $100 \mathrm{~cm}$ in length) housed in a single-zone furnaceas shown in Figure 1. 


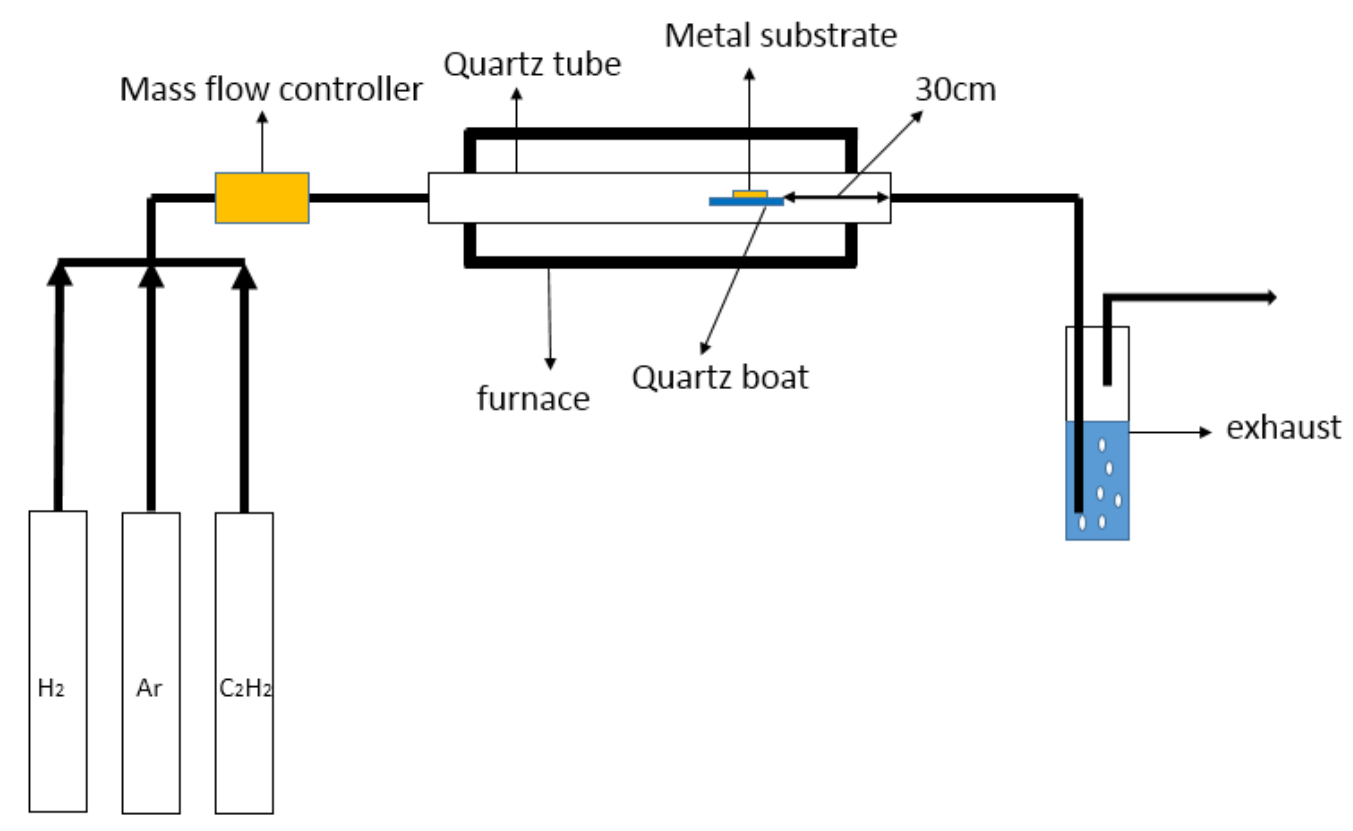

Figure 1.Experimental setup for aligned CNT synthesis by chemical vapor deposition.

The position of quartz boat ( $4 \mathrm{~cm}$ wide and $7 \mathrm{~cm}$ long) was placed in the quartz tube $30 \mathrm{~cm}$ to the tail, where the acetylene can be deposited better. The substrates used in this study were placed in the middle of the boat. Argon flow in the quartz tube about $5 \mathrm{~min}$ to exhaust air in tube. Then, the CVD reactor was heated and the reaction started in the CVD reactor at room temperature. Hydrogen was inlet into the reactor at different temperatures $\left(500^{\circ} \mathrm{C}, 560^{\circ} \mathrm{C}\right.$ and $\left.620^{\circ} \mathrm{C}\right)$. CVD growth of aligned CNTs was carried out at about $750-850{ }^{\circ} \mathrm{C}$ when the source gases were inlet with the flow ratesof 24, 142 and 303sccm (standard cubic centimeter per minute) for acetylene, hydrogen, and argonrespectively. The flow of the ethylene/hydrogen/argon mixture was maintained for the entire growth period ranging from 10 to 60 minutes on different substrates.

\section{Results and Discussion}

\section{Effect of Different Temperature to Supply H2}

Here we have synthesized VACNTs on various substrates.For the effect of $\mathrm{H}_{2}$ inlet at different temperature, we use copper as the sample to explore the mechanism.

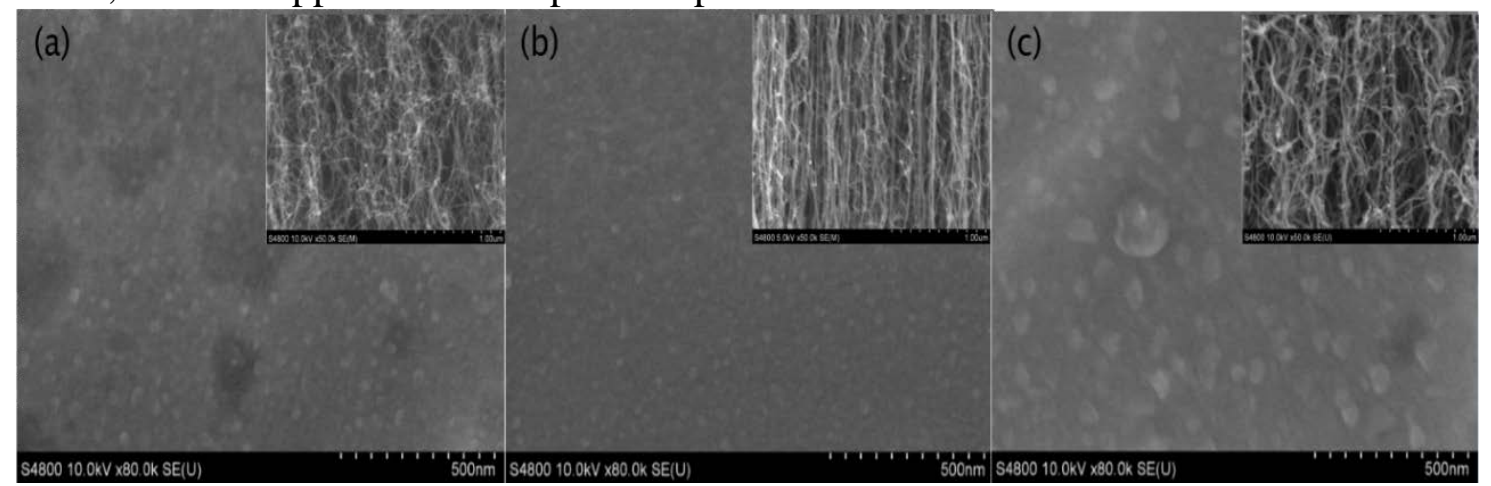

Figure 2.SEM images of the catalyst morphology and aligned CNT layer on copper foil, in which $\mathrm{H} 2$ wereinlet at different temperature (a) $500^{\circ} \mathrm{C}$ (b) $560^{\circ} \mathrm{C}$ (c) $630^{\circ} \mathrm{C}$

Figure 2 shows that the morphology of catalyst and aligned CNT layer on copper foil, in which $\mathrm{H}_{2}$ were inlet at different temperature. From the results, we can see the catalyst particles are more 
uniform when inletting $\mathrm{H}_{2}$ at $500^{\circ} \mathrm{C}$ and much denser aligned $\mathrm{CNTs}$ were obtained. Ostwald ripening occurred when $\mathrm{H}_{2}$ was inlet at $630^{\circ} \mathrm{C}$ due to the surface tension between the particles,whichmakes small particles incorporate in large particles and leads to messy CNT arrays.

\section{Effect of Growth Time}

Also use copper as the sample,Figure3 shows SEM images of CNTs grown on the copper foil substrate for different growth times. The relationship between the thickness of the aligned CNT film and the growth time at $750{ }^{\circ} \mathrm{C}$ is shown in (g). The growth time was from $5 \mathrm{~min}$ to $60 \mathrm{~min}$. The decreased growth rate could be attributed to the catalyst lost of activity.
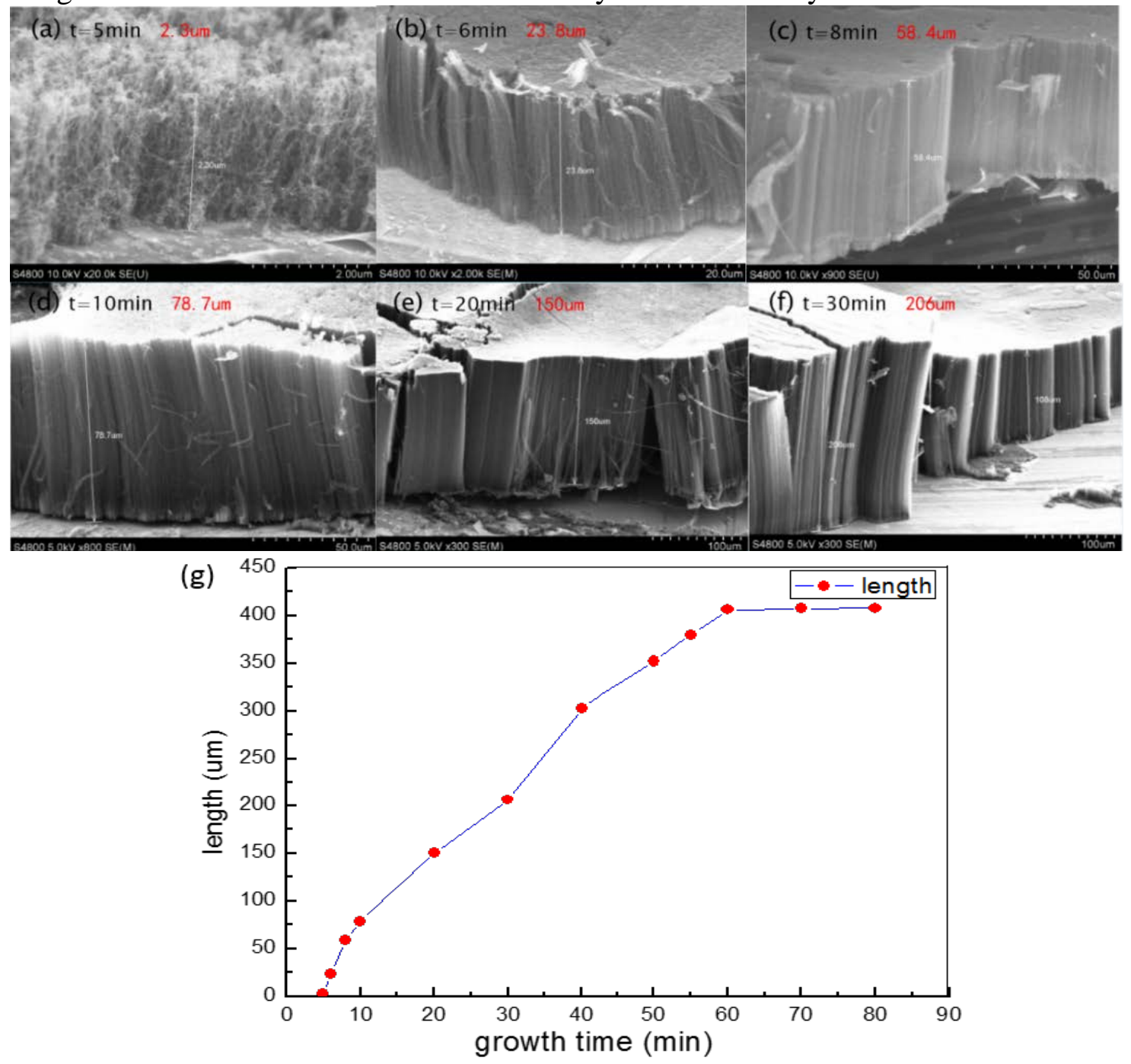

Figure 3. SEM images of aligned CNT layer on copper foil substrate for various growth times: (a) 5min, (b) 6min, (c) 8min, (d) 10 min,(e)20min and (f)30min,(g) Effect of growth time on CNT film thickness. (23sccm C2H2,143sccm H2,303sccm Ar; growth temperature, $750{ }^{\circ} \mathrm{C}$.) 


\section{Effect of Growth Temperature}
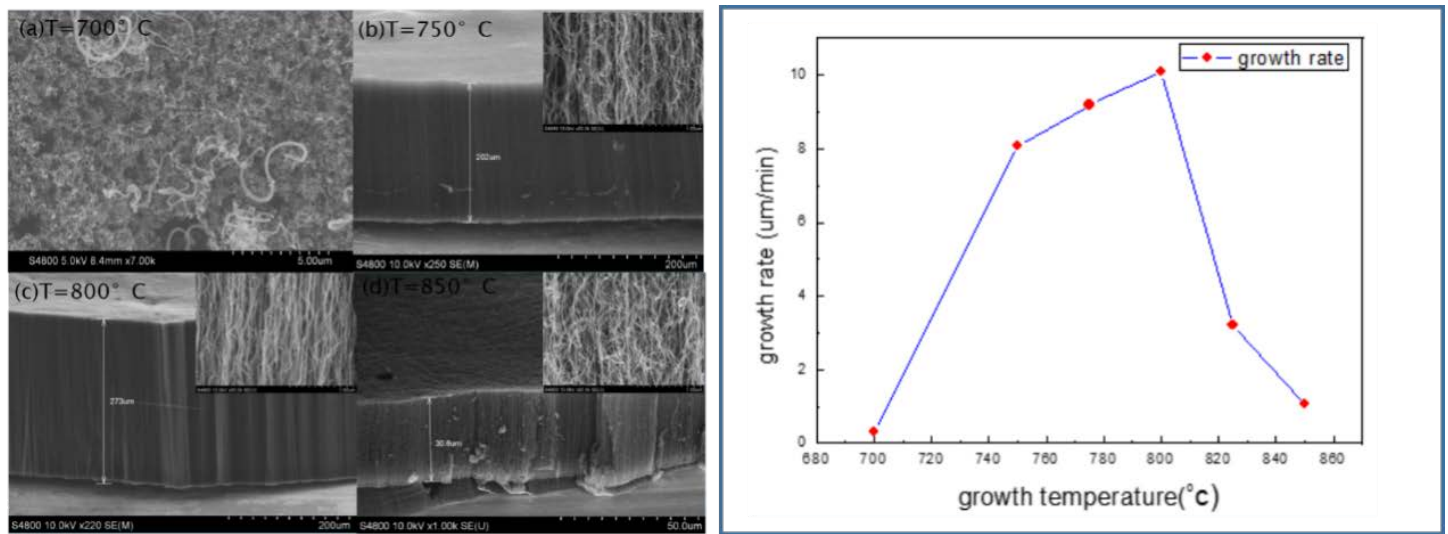

Figure4. SEM images of aligned CNT layer on copper substrate grown at different temperatures: (a) $700^{\circ} \mathrm{C}$, (b) $750^{\circ} \mathrm{C}$, (c) $800^{\circ} \mathrm{C}$, and (d) $850{ }^{\circ} \mathrm{C}$.(g) Effect of growth temperature on growth rate.

(23sccm C2H2,143sccm H2,303sccm Ar; growth time, 25 min.)

Figure 4showsSEM images of CNTs grown on copper foil substrate at increasing growth temperatures. At $700^{\circ} \mathrm{C}$, the temperature was not sufficiently high for the acetylene to be deposited on the substrate, and no aligned CNTs were found (Figure 4a).At a temperature of $800^{\circ} \mathrm{C}$, the aligned CNT film was $272 \mu \mathrm{m}$, and the growth rate was $10.09 \mu \mathrm{m} / \mathrm{min}$, which was faster than other arrays $\left(8.08 \mu \mathrm{m} / \mathrm{min}, 750^{\circ} \mathrm{C} .1 .06 \mu \mathrm{m} / \mathrm{min}, 850^{\circ} \mathrm{C}\right)$. What's more, much longer and denser aligned CNTs were obtained at $800^{\circ} \mathrm{C}$. The relationship between the growth rate of the CNT layer and the growth temperature is shown in(g) Figure 5.

\section{Effect of Different Substrate}

$30 \mathrm{~nm}$ buffer layer $\left(\mathrm{Al}_{2} \mathrm{O}_{3}\right)$ and $2 \mathrm{~nm}$ catalyst $(\mathrm{Fe})$ catalyst system are deposited on copper foil、iron foil v copper column and iron column, and we have synthesized aligned multiwalled carbon nanotubes (MWCNTs) on all of them. Figure 5shows different thickness on different metal substrate and the pattern of the arrays. It is clear that the diameter of CNTs on iron substrate were thicker than other substrates. It was also verified by TEM(Figure 6)and the detailed structure of the CNTs also was studied by it. We foundthat the CNTs were of different sizes but had a similar structure because of same thickness of catalyst and buffer layer. The thickness of CNT on iron column reached $1.03 \mathrm{~mm}$, which is relatively high CNT arrays on metal substrate to date.

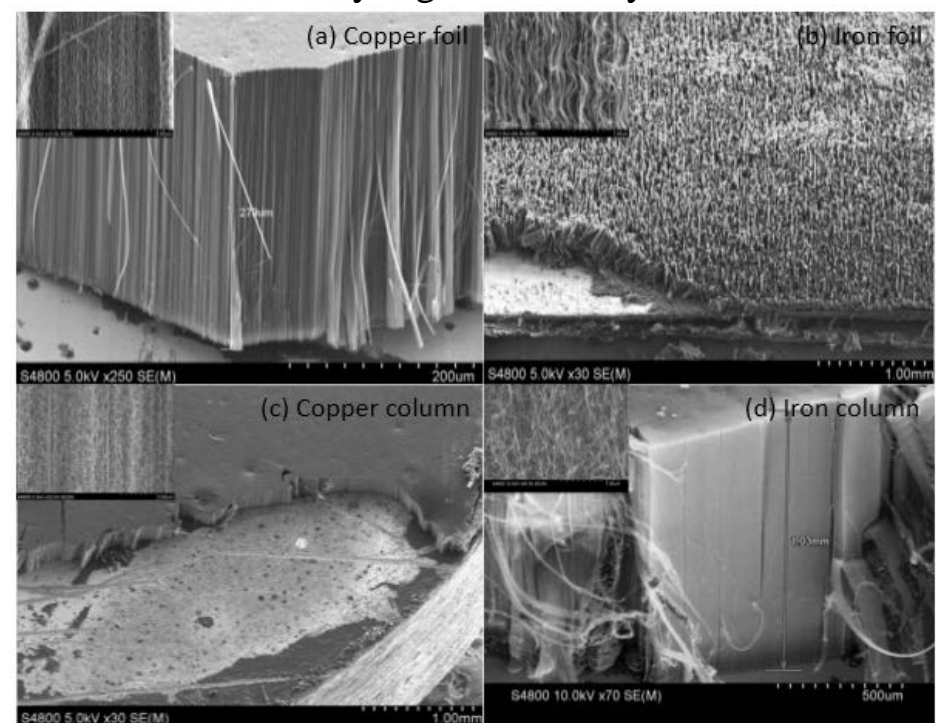

Figure5. SEM images of aligned CNT layer on different substrate

However, as the mixture of amorphous carbon and CNTs, CNT arrays on iron foil and iron 
column have more defects than the array on copper foil and copper column. As in Figure 7, Raman spectra show that CNTs on copper foil were better than other metal substrates.

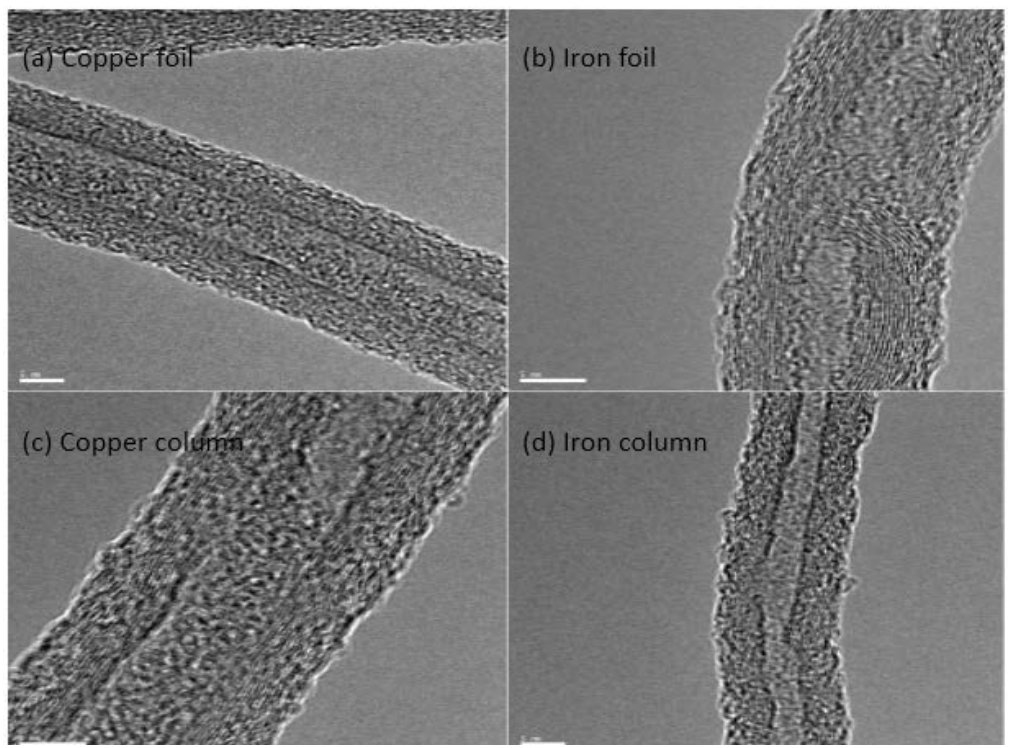

Figure 6. Detailed structure of aligned CNTs by TEM

We can see that the purity of CNT on iron foil was low and defects on column were more than on foil. The intensity ratio between bands D and G (ID/IG) is 0.6 and 0.8 for CNTs grown on copper foil and copper column, while for CNTs grown on iron foil and iron column ID/IG is higher than 1.0.So we can illustrate the higher degree of defects for CNTs grown on iron substrate.
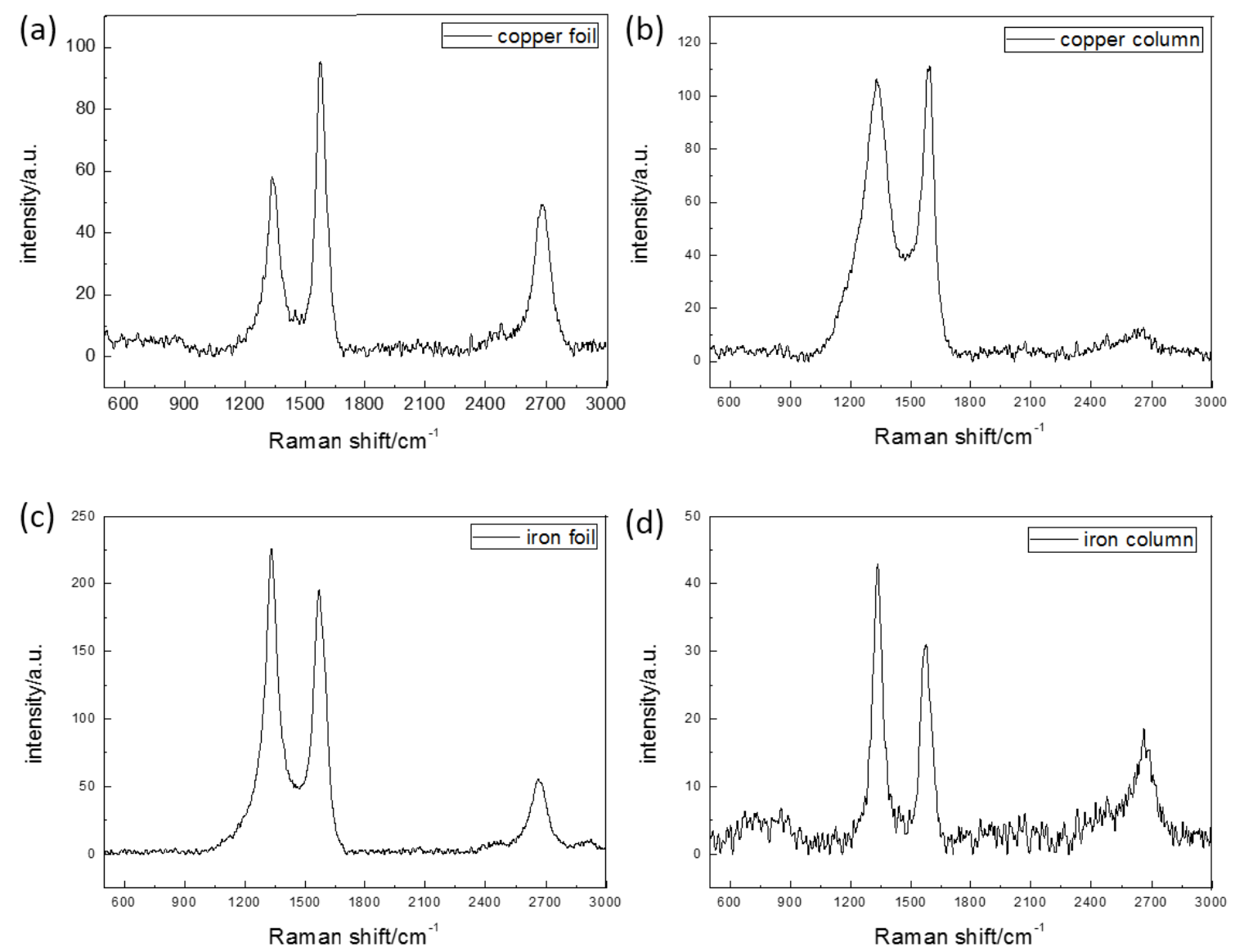

Figure 7. Raman spectra of aligned CNTs 


\section{Conclusions}

Because of the high surface energy, it was a big challenge to synthesize better CNTs on metal substrates. Fortunately, we have achieved this goal and successfully grew aligned MWCNTs on different metal substrate by depositing optimal 30nm buffer layer $\left(\mathrm{Al}_{2} \mathrm{O}_{3}\right)$ and $2 \mathrm{~nm}$ catalyst (Fe) catalyst in this system. Ostwald ripening easily occurred that Hzinlet at $630^{\circ} \mathrm{C}$.SEM and TEM showed that the diameter of CNTs on iron foil and iron column wider than on copper. With this proportionate gas $\left(23 \mathrm{sccm} \mathrm{C}_{2} \mathrm{H}_{2}, 143 \mathrm{sccm} \mathrm{H}_{2}, 303 \mathrm{sccm} \mathrm{Ar}\right)$ and proper growth temperature $\left(800^{\circ} \mathrm{C}\right)$,longer and better arrays were obtained $(>1 \mathrm{~mm})$ on metal substrate that were relatively high to date. This work can be extended in other different metal substrates. Our efforts in these directions are now underway.

\section{Acknowledgement}

This work was supported by the National Natural Science Foundation of China (No. 11574395), the Research Programe of the National University of Defense Technology (No. JC15-02-01), the open foundation of State Key Laboratory of high Performance Computing (No. 201301-02), and the open foundation based on the innovation platform of Hunan key laboratories (No. 13 k022).

\section{References}

[1] Lijima, S. Nature 1991, 354, 56.

[2] Hone, J.; Whitney, M.; Piskoti, C.; Zettl, A. Phys. ReV. B 1999,59, R2514.

[3] Dai, H. J.; Wong, E. W.; Lieber, C. M. Science 1996, 272, 523.

[4] Treacy, M. M.; Ebbesen, T. W.; Gibson, J. M. Nature 1996, 381,678.

[5] R. H. Baughman, A. A. Zakhidov, and W. A. de Heer, Science, vol. 297, Aug. 2002.

[6] A. P. Graham, G. S. Duesberg, R. V. Seidel, M. Liebau, E. Unger, W.Pamler, F. Kreupl, and W. Hoenlein, Small, vol. 1, Apr. 2005.

[7] T. W. Ebbesen, H. J. Lezec, H. Hiura, J. W. Bennett, H. F. Ghaemi,and T. Thio,Nature, vol. 382, Jul. 1996.

[8] E. Pop, D. Mann, Q. Wang, K. Goodson, and H. J. Dai, Nano Lett., vol. 6, Jan. 2006.

[9] Z. Liu, X. M. Sun, N. Nakayama-Ratchford, and H. J. Dai .Acs Nano, vol. 1, Aug.2007.

[10] S. J. Tans, A. R. M. Verschueren, and C. Dekker,Nature, vol. 393, May 1998.

[11] Park D, Kim Y H, Lee J K.Carbon,2003,41:1025

[12] Choi W B, Lee Y H, Lee N S et al. Jpn J Appl Phys,2000,39:60

[13] Croci M, Arfaoui I, Stockli T et al. Mcroelectron.J,2004,35:329

[14] Kim, P.; Shi, L.; Majumdar, A.; McEuen, P. L. Phys. ReV. Lett.2001, 87, 215502-1

[15] Garcia-Cespedes, J.; Thomasson, S.; Teo, K. B. K.; Kinloch, I.A.; Milne, W. I.; Pascual, E.; Bertran, E. Carbon 2009, 47, 613-621.

[16] B. A. Wang, X. Y. Liu, H. M. Liu, D. X. Wu, H. P. Wang, J. M. Jiang, X.B. Wang, P. A. Hu, Y. Q. Liu, and D. B. Zhu,J. Mater. Chem., vol. 13, 2003.

[17] F. S. Xu, X. F. Liu, and S. D. Tse, Carbon, vol. 44, Mar. 2006.

[18] W. Hofmeister, W. P. Kang, Y. M. Wong, and J. L. Davidson, J.Vac. Sci. Technol. B, vol. 22, May-Jun. 2004.

[19] M. Karwa, Z. Iqbal, and S. Mitra, Carbon, vol. 44, Jun. 2006. 
[20] S. Talapatra, S. Kar, S. K. Pal, R. Vajtai, L. Ci, P. Victor, M. M. Shaijumon, S. Kaur, O. Nalamasu, and P. M. Ajayan, Nature Nanotechnol., vol.1, Nov. 2006.

[21] L. J. Gao, A. P. Peng, Z. Y. Wang, H. Zhang, Z. J. Shi, Z. N. Gu, G.P. Cao, and B. Z. Ding, Solid StateCommun., vol. 146, Jun. 2008

[22] X. W. Yin, Q. L. Wang, C. G. Lou, X. B. Zhang, and W. Lei, Appl. Surface Sci., vol. 254, Aug. 2008.

[23] Pan Z Y,et al . [J]. Nature,1998,394(6694):631

[24] Hata K, Science,2004,306(5700):1362

[25] Li X S, et al. Nano technology,2008,19(45):45569-1 